\title{
Multivariate analysis as a tool for selecting the vine pruning pretreatment towards the highest enzymatic hydrolysis yield
}

\author{
Elenilson G. Alves Filho ${ }^{\text {a, }}$, Tatiane C. Maciel ${ }^{\mathrm{b}}$, Eduardo Gudiña ${ }^{\mathrm{c}}$, Emilio C. Miguel ${ }^{\mathrm{d}}$, \\ Ligia R. Rodrigues ${ }^{c}$, Sueli Rodrigues ${ }^{\mathrm{a}, \mathrm{b}}$ \\ ${ }^{a}$ Federal University of Ceará, Department of Food Engineering, Biotechnology Laboratory, Campus do Pici, Bloco 851, 60440-900, Fortaleza-CE, Brazil \\ ${ }^{\mathrm{b}}$ Federal University of Ceará, Department of Chemical Engineering, Campus do Pici, Bloco 709, 60440-900, Fortaleza-CE, Brazil \\ ${ }^{c}$ Centre of Biological Engineering - CEB, University of Minho, 4710-057, Braga, Portugal \\ ${ }^{\mathrm{d}}$ Federal University of Ceará, Physical Department/Central analytical, Brazil
}

\section{A R T I C L E I N F O}

\section{Keywords:}

Cellulase

Enzyme hydrolysis

Vine pruning

Chemometrics

\begin{abstract}
A B S T R A C T
Lignocellulosic materials require pretreatment to remove lignin enabling the enzyme access to the cellulose. This work used multivariate analysis to investigate the acid and alkali pretreatments of vine pruning followed by enzymatic hydrolysis. The best acid pretreatment conditions were $\mathrm{H}_{2} \mathrm{SO}_{4} 1.5 \%, 120{ }^{\circ} \mathrm{C}$ for 30 min, removing $68.7 \%$ of hemicellulose, enabling $95.8 \%$ of cellulose recovery. However, this treatment was not enough to allow the enzyme hydrolysis. A second step of treatment with $\mathrm{NaOH} 3.0 \%$ at $120{ }^{\circ} \mathrm{C}$ without agitation for $60 \mathrm{~min}$ led to a material with $75.0 \%$ of cellulose and $25.0 \%$ of lignin. However, the lowest glucose yield $(80.86 \%$ and $32.26 \mathrm{~g}$ $\mathrm{L}^{-1}$ of glucose) was obtained after the enzyme hydrolysis of this material. The highest glucose yield $(98.72 \%$ with $35.06 \mathrm{~g} \mathrm{~L}^{-1}$ ) was obtained using a pretreated material containing $68.1 \%$ of cellulose and $31.9 \%$ of lignin obtained after a milder condition $\left(\mathrm{NaOH} 2 \%\right.$ at $\left.100{ }^{\circ} \mathrm{C}\right)$, thus showing that not all the lignin need to be removed to obtain a high saccharification yield. A less severe pretreatment with no adverse effect on the glucose yield with the advantage of preserving the non-cellulose biomass fractions was effective for vine prune valorization.
\end{abstract}

\section{Introduction}

Some European countries have a long tradition of wine production [1]. In 2015, France, Italy, Spain, Germany, and Portugal were responsible for $70 \%$ of worldwide wine production (26 billion liters). Among these countries, Portugal is the fifth largest producer with a production of 705 million liters in that year, according to Instituto $d a$ Vinha e Vinho (https://www.ivv.gov.pt/np4/home.html accessed on May 21, 2019). Annually, the vineyard trees are pruned to increase the productivity and the grape quality for the next harvest [2]. In the pruning process, the cut thin branches are often burned [3], which may cause environmental problems related to the lignin combustion [4]. Some studies based on the production of wood-based panels [5]; vine pruning gasification [6]; lactic acid production by fermentation of the hemicellulose sugars [4,7]; biosurfactants production by fermentation of the cellulose sugars [3] were previsouly descibed.

The use of lignocellulosic biomass as a raw material for biofuels and biomaterials production increased [8]. At first, the lignocellulosic biomass was considered a source of glucose for ethanol production by fermentation. However, according to the biorefinery concept, the lignocellulosic biomass is now considered a raw material for many different industrial processes [9]. The industrial application of non-cellulose (hemicellulose and lignin) fractions are also a target in recent studies. Therefore, the use of all fractions of these materials, such as sugars from hemicellulose, cellulose, and lignin, to produce value-added products makes the transformation of biomass economically attractive [9].

The lignocellulosic materials are composed of an aromatic polymer (lignin) and carbohydrates polymers such as cellulose and hemicellulose, which are hydrolyzed to xylose and glucose, respectively [10]. Due to its composition, lignocellulosic materials are highly resistant to degradation. Therefore, the first step of the biomass transformation process is a pretreatment of the residue that results in the chain opening and the lignin and hemicellulose release [11,12]. The pretreatment might also reduce the cellulose crystallinity, increasing the amorphous cellulose fraction, which makes the cellulose available to be converted by enzymes action [13].

Due to the complexity of the lignocellulosic material, there is not a

\footnotetext{
* Corresponding author.

E-mail address: elenilson.godoy@yahoo.com.br (E.G. Alves Filho).
} 
single pretreatment that is equally effective for all of them [14]. Therefore, whenever selecting a pretreatment, it is essential to consider some factors, such as digestibility of the treated material, sugars recovery, the presence of inhibitors, and the energy expenditure [15]. This pretreatment step is crucial for bioprocess development and sustainability because it may comprise $20 \%$ of the total costs in the production process [16]. The acid hydrolysis removes the hemicellulose and can solubilize a small fraction of lignin. Nonetheless, most of this polymer remains in the solid fraction, and therefore, another treatment step is necessary to remove the remaining lignin [14]. Afterward, the resultant material can be subjected to enzymatic hydrolysis to release the monomeric sugars (e.g. glucose), used in fermentation processes [10].

Although alkali treatment can be applied to remove lignin and hemicellulose from biomass, it also breaks lignin $\beta-O-4$ and $\alpha-O-4$ bonds, resulting in several phenolic hydroxyl groups. The treatment severity depends on the material composition, and long treatment times are frequently needed. As reported by Lorenci et al. (2020), the alkali pretreatment presents some disadvantages, including high concentration processing media, low cellulose yields, high production of toxic compounds, and generation of polluting residues [17]. Besides, alkali treatment does not allow the use of non-cellulosic fractions (hemicellulose and lignin), which presents a great potential of application in other industries.

On the other hand, biomass processing at mild concentration and temperature conditions, either acid or sequential acid and alkaline, allows the recovery and utilization of the three main fractions of lignocellulosic biomass. The processing is conducted in at least two steps to selectively separate the sugars from hemicellulose, dissolve the lignin and recover less crystalline cellulose for enzyme hydrolysis. The twostep mild acid-alkali pretreatments enhance the biomass enzyme hydrolysis and fermentability. The disadvantages of such processing include additional processing steps; additional research to enhance the whole process and the utilization of biomass constituents [17]. Due to the low yields obtained from some pretreatments [18], in the current work, the effect of acid-alkali two-steps for pretreatment of vine pruning is evaluated.

Therefore, the resultant cellulosic fraction from the solid material was submitted to enzymatic hydrolysis, and the hydrolysis yields were determined since the glucose concentrations obtained from the hydrolysis are relevant to select the most appropriate pretreatment conditions for a given fermentation process. Scanning Electron Microscopy (SEM) allowed to visualize the pretreatment effect on the vine prune biomass and correlate the chemical composition of each portion with the material structure. The SEM images demonstrate that even with residual lignin, the acid-alkali pretreatment was able to open the material structure allowing the enzyme to reach the cellulose portion producing high glucose yields.

\section{Materials and methods}

\subsection{Vine pruning}

The vine pruning used for study development was kindly donated by a local farm in the Minho's province, Portugal. The residue was ground in a knife mill and dried in an oven at $60^{\circ} \mathrm{C}$ for $24 \mathrm{~h}$ before use.

\subsection{Acid pretreatment of the vine pruning residue}

A pretreatment with sulfuric acid $\left(\mathrm{H}_{2} \mathrm{SO}_{4}\right)$ was applied to the vine pruning residue according to a central composite design (CCD) that enabled the definition of the adequate experiments covering a relevant experimental domain. The relevant variables were temperature $\left(100{ }^{\circ} \mathrm{C}\right.$ to $120^{\circ} \mathrm{C}$ ), time $(15-45 \mathrm{~min})$, and the percentage of $\mathrm{H}_{2} \mathrm{SO}_{4}(0.5 \%-2.5 \%$ $\mathrm{v} / \mathrm{v})$. The biomass was impregnated with the acid solution at a solid/ liquid ratio of 1:20 (w/v). The experimental domain was selected based on previous reports of acid pretreatment of olive tree pruning [19], almond tree pruning [20], and vine pruning [4]. $\mathrm{H}_{2} \mathrm{SO}_{4}$ was of analytical grade (Synth Chemicals, São Paulo - Brazil).

After each treatment, the solid and liquid fractions were separated by vacuum filtration using a Buchner funnel with a soft cloth, and the solid fraction was washed until neutral $\mathrm{pH}$ and weighted, which was represented as total mass recovery (TMR) calculated according to Equation (1). The wet material was stored at $10{ }^{\circ} \mathrm{C}$ until further use in the hydrolysis experiments.

$\operatorname{TMR}(\%)=\frac{\text { mass of the solid }(\text { insoluble }) \text { fraction }(g)}{\text { initial mass }(g)} \times 100 \quad$ Equation 1

where the "mass of the solid (insoluble) fraction" corresponds to the mass recovered after filtration and successive washings, and the "initial mass" is the mass of the residue before treatment.

Changes in the cellulose, hemicellulose, and lignin contents due to processing were determined by the chemical composition of the treated material. The experimental condition with a higher percentage of lignin removal along with minimum cellulose and hemicellulose solubilization was selected for the subsequent alkali treatment. The concentration of sugars (cellobiose, glucose, xylose, arabinose), acetic acid, furfural, hydroxymethylfurfural (HMF) was also determined in the liquid fraction after the acid pretreatment. The analytical methods are described in detail on section 2.5 .

\subsection{Alkaline treatment of the vine pruning residue}

As previously described (section 2.2), the pretreatment with sodium hydroxide $(\mathrm{NaOH})$ was carried out on the material obtained from the best conditions of the acid pretreatment to promote the residue delignification. Three different $\mathrm{NaOH}$ solutions (1.0\%, 2.0\%, and $3.0 \%$ $\mathrm{w} / \mathrm{v}$ ) were used at $120^{\circ} \mathrm{C}$ without agitation (autoclave), and at $100{ }^{\circ} \mathrm{C}$ with agitation in a stirred-heating plate (MS7-H550-S LAB 1000). All the experiments were carried out with a substrate to alkali solution ratio (w/ v) of 1:20 during $60 \mathrm{~min}$. After each treatment, the solid and liquid fractions were separated by filtration in a fabric cloth under vacuum, and the solid fraction was washed until $\mathrm{pH} 7.0$, and stored at $4{ }^{\circ} \mathrm{C}$. Subsequently, the chemical composition of the treated material (percentages of cellulose, hemicellulose, and lignin) was determined (described in section 2.5), and the TMR (\%) was calculated as described in section 2.2. All samples obtained in this step were further submitted to enzymatic hydrolysis for the selection of the most appropriate conditions. $\mathrm{NaOH}$ of analytical grade was purchased from Synth Chemiclas (Synth, São Paulo - Brazil).

\subsection{Enzymatic hydrolysis}

Lignocellulosic materials are composed of lignin and several mutually entangled and chemically bonded carbohydrate polymers that require multiple enzymes working together synergistically towards a complete hydrolysis. Thus, enzymatic hydrolysis was performed using the commercial enzymes Cellic ${ }^{\mathrm{TM}} \mathrm{CTec} 2$ and Novozyme 188, both purchased from Sigma-Aldrich Brazil. Cellic ${ }^{\mathrm{TM}}$ CTec2 contains $\beta$-glucosidases and xylanase as the major enzyme activity and, its activity is expressed as Filter paper Unit (FPU). Cellulosic enzymes, such as Cellic ${ }^{\mathrm{TM}} \mathrm{CTec} 2$, usually lack cellobiase and are strongly affected by feedback inhibition due to the cellobiose content increase in the reaction medium as the cellulose hydrolysis proceeds. Thus, Novozyme 188 (cellobiase) is used as a supplementary enzyme to assure a synergistic effect avoiding feedback inhibition and allowing the complete hydrolysis. Novozyme 188 activity is expressed as Cellobiase Unit (CBU). The enzyme loads were $30 \mathrm{FPU} / \mathrm{g}$ of biomass of Cellic ${ }^{\mathrm{TM}} \mathrm{CTec} 2$ ) and $15 \mathrm{CBU} /$ $\mathrm{g}$ of biomass of Novozyme 188, both added at the beginning of the hydrolysis. The assays were performed in Erlenmeyers of $100 \mathrm{~mL}$ with a reaction volume of $40 \mathrm{~mL}$ of a mixture containing sodium citrate $(\mathrm{pH}$ 5.0 ), sodium azide $(0.1 \%, w / v)$, enzymes, and $5 \%(w / v)$ of biomass. As 
previous studies reported that the relationship between the initial solid content and sugar conversion after the enzymatic hydrolysis has a nearly linear behavior in the $5-40 \%$ range of the solid loading, the results herein obtained are considered reliable if industrial applications are envisaged [21]. The assays were carried out in a rotatory shaker

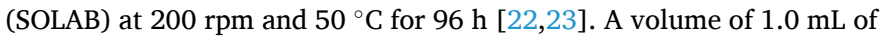
the resultant samples were collected every $24 \mathrm{~h}$ and kept in boiling water for $5 \mathrm{~min}$ for enzymes inactivation. Then, the samples were centrifuged at $12,000 \times g$ for $20 \mathrm{~min}$ to separate the insoluble fraction. The soluble fraction was filtered through a $0.2 \mu \mathrm{m}$ membrane filter and stored frozen to determine the hydrolysis products further. The untreated vine pruning was also submitted to hydrolysis. The control experiments were carried out without enzyme addition. The hydrolysis was performed in triplicate. The enzymatic hydrolysis yield (yield of the cellulose/hemicellulose to glucose conversion) was calculated according to the equation proposed by the National Renewable Energy Laboratory [24], as presented in Equation (2):

Enzymatic cellulose conversion $(\%)=\left(\frac{[\text { glucose }]+1.05[\text { cellobiose }]}{1.11 \mathrm{f}[\text { biomass }]}\right) * 100$

Equation 2

where [glucose] is the glucose concentration (g. $\left.\mathrm{L}^{-1}\right)$; [cellobiose] is the cellobiose concentration (g. $\mathrm{L}^{-1}$ ); [biomass] is the dry biomass concentration at the beginning of the enzymatic hydrolysis $\left(\mathrm{g} . \mathrm{L}^{-1}\right) ; f$ is the cellulose fraction in dry biomass $\left(\mathrm{g} \cdot \mathrm{g}^{-1}\right) ; 1.05$ is the factor that converts cellobiose into equivalent glucose, and 1.11 is the factor that converts cellulose to equivalent glucose.

\subsection{Analytical methods}

The chemical composition of the untreated and treated vine pruning residue was determined according to the analytical protocol described by the National Renewable Energy Laboratory (NREL). The sugars and lignin were determined after the biomass acid hydrolysis. The biomass was submitted to acid hydrolysis with sulfuric acid $\left(\mathrm{H}_{2} \mathrm{SO}_{4}\right) 72 \%(\mathrm{v} / \mathrm{v})$ at $30{ }^{\circ} \mathrm{C}$ for $1 \mathrm{~h}$. The mixture was diluted with water up to $4.0 \%(\mathrm{v} / \mathrm{v})$ of acid and autoclaved at $120^{\circ} \mathrm{C}$ for $60 \mathrm{~min}$. Afterward, the solid fraction containing the acid-insoluble lignin (Klason lignin) was separated from the liquid fraction containing sugars and the acid-soluble lignin by filtration in sintered glass funnel (porous plate $\mathrm{n}^{\circ} 2$ ). The Klason lignin was gravimetrically determined, and the acid-soluble lignin was determined using a UV-visible spectrophotometer at 215 and $280 \mathrm{~nm}$ [25]. The concentrations of cellobiose, glucose, xylose, arabinose, acetic acid, furfural, and hydroxymethylfurfural (HMF) were determined by high-performance liquid chromatography (HPLC) - Agilent 1260 infinity system equipped with a refractive index and UV-visible detector (Wilmington, Delaware, EUA). The separation was performed using an Aminex HPX-87H (Bio-Rad Laboratories Inc., America) column. The mobile phase was $5 \mathrm{mmol} \mathrm{L}^{-1}$ of sulfuric acid, the flow rate was $0.7 \mathrm{~mL}$ $\mathrm{min}^{-1}$, and the column temperature at $60{ }^{\circ} \mathrm{C}$. The acid acetic, furfural, and HMF were UV detected at $285 \mathrm{~nm}$, and sugars were detected by refraction index at $35^{\circ} \mathrm{C}$.

The biomass extractives were extracted by the Soxhlet method (Soxtec ${ }^{\mathrm{TM}}$ 8000) in a two-step protocol: first with distilled water; and second with ethanol $95 \%(\mathrm{v} / \mathrm{v})$. Both extractions were carried out for 6 $\mathrm{h}$ at $80{ }^{\circ} \mathrm{C}$ without agitation. The mass of extractives was quantified by gravimetry [25].

The ash content was determined through dry oxidation of the biomass in a muffle at $575{ }^{\circ} \mathrm{C}$ for $4 \mathrm{~h}$, and was quantified by gravimetry [25]. The concentration of cellobiose, glucose, and xylose arabinose released from the enzymatic hydrolysis was measured by HPLC (Agilent 1260 infinity, Wilmington, Delaware, EUA) previously described. All HPLC standards (cellobiose, glucose, xylose, arabinose, acetic acid, furfural, and hydroxymethylfurfural) were purchased from Sigma-Aldrich, Brazil.

\subsection{Structural changes in the biomass}

To visualize the structural changes on the vine pruning surface from the treatments and enzymatic hydrolysis, a morphological study was carried out by Scanning Electron Microscope (SEM) using a Quanta 450 FEG - FEI equipment. The samples were freeze-dried to remove the moisture and then, fixed in a stub. Before analysis, the samples were coated with a thin layer of gold in a metalizer (Quorum QT150ES). The raw material surface was also analyzed.

\subsection{Statistics analysis of the data}

\subsubsection{Experimental design}

To assess the effect and the interactions among the three independent variables (temperature, time, and percentage of sulfuric acid) in lignin, cellulose, and cellulose, removal two Central Composite Rotatable Designs (CCRD) were built with three replicates at the central point. Cellulose and hemicellulose were evaluated together since they can be hydrolyzed to sugars monomers [18].

\subsubsection{Univariate analysis}

Analysis of Variance by ANOVA was performed on experimental triplicate using the software Statistica 10.0 (Statsoft) to statistically certify the differences among the concentrations of glucose and the respective enzymatic hydrolysis yield using the Tukey's test and F-test as significant criteria. The results are expressed as mean \pm standard deviation (SD).

\subsubsection{Multivariate analysis}

In general, unsupervised chemometric analysis as Principal Component Analysis (PCA) is used to explore the dataset, reaching correlations among the experimental variables and samples. Therefore, PCA modeling was applied on each type of vine pruning processing, namely acid pretreatment; alkaline pretreatment; and enzymatic hydrolysis. Each numerical matrix was imported and autoscaled using the software Matlab $^{\mathrm{TM}}$ with PLS Toolbox package (8.6.1 - Eigenvector Research Inc., Wenatchee, USA). The resultant matrices were decomposed using the SVD (Singular Value Decomposition) algorithm, and relevant Information was obtained on the first two Principal Components (PC) for all the analyses, with $95 \%$ of confidence level $[26,27]$.

\section{Results and discussion}

\subsection{Raw vine pruning}

The composition of the vine pruning residue was $36.0 \%(w / w)$ of cellulose, $29.6 \%(\mathrm{w} / \mathrm{w})$ of lignin, $21.8 \%(\mathrm{w} / \mathrm{w})$ of hemicellulose $(\mathrm{w} / \mathrm{w})$, which presents xylose as structural monomer, $8.6 \%(\mathrm{w} / \mathrm{w})$ of extractives, and $3.6 \%(\mathrm{w} / \mathrm{w})$ of ash. These values are in good agreement with a previous report for the composition of vine pruning from Galicia (Spain) [4]. Because the cellulose hydrolysis product is glucose (a ready fermentable sugar for several microorganisms), the high cellulose content makes vine prune an interesting biomass for fermentation processing after saccharification.

\subsection{Acid pretreatment of the vine pruning residue}

The evaluation of the pretreatment with sulfuric acid $\left(\mathrm{H}_{2} \mathrm{SO}_{4}\right)$ was performed according to the Central Composite Rotatable Design (CCRD). After the acid pretreatment, two fractions were obtained: the solid fraction, expressed as the total mass recovery (TMR) containing the cellulose, lignin, and hemicellulose not solubilized during the treatment; and the liquid fraction containing all the soluble components (raw data is available in Table S1 - Supporting Information). Considering that the target material is the solid fraction, the CCRD was used to evaluate the composition responses to experimental parameters changes just for the 
solid fraction. The experimental responses relative to lignin showed a significant effect of sulfuric acid and temperature on the lignin content in the solid fraction. The experimental responses were evaluated for cellulose and hemicellulose content together because both carbohydrates can be hydrolyzed to sugar monomers [18]. The results showed a significant effect of the sulfuric acid, temperature, and time in the solid fraction. The linear effect of the acid concentration on the hemicellulose solubilization was positive and exhibited the most significant effect. The positive sign of this variable means that when the acid concentration increase, the hemicellulose solubilization also increase. This evidence corroborates that this type of treatment tends to increase the enzymes' accessibility to cellulose [28]. The fitted model to predict the solubilized hemicellulose as a function of the independent variables is given by Equation (3):

$y=65.5-3.7 X_{1}+45.5 X_{2}+3.9 X_{3}$

Equation 3

where the " $y$ " corresponds to the solubilized hemicellulose percentage; and $\mathrm{X}_{1}, \mathrm{X}_{2}$, and $\mathrm{X}_{3}$ are the temperature, acid concentration, and time of the pretreatment, respectively.

Given the elevate number of assays, experimental responses, and variables (time, temperature, and percentage of sulfuric acid), an unsupervised chemometric method by Principal Component Analysis (PCA) was developed to better understand the composition changes of the solid fractions after different pretreatments. Fig. 1 presents the PC1 $\times$ PC2 scores coordinate system (left side) and the respective loadings (right side), which retained $81.32 \%$ of the total data variance.

According to the PC1 axis, the percentage of sulfuric acid $\left(\mathrm{H}_{2} \mathrm{SO}_{4}\right)$ was the main factor for the assay's discrimination, followed by temperature and time. In general, the lignin and cellulose content increased with the increase of temperature, time, and percentage of $\mathrm{H}_{2} \mathrm{SO}_{4}$. The cellulose content was higher using $1.5 \%$ of $\mathrm{H}_{2} \mathrm{SO}_{4}$, while lignin content was higher using $2.5 \%$ of this acid. On the other hand, using the lowest percentage of $\mathrm{H}_{2} \mathrm{SO}_{4}(0.5 \%)$, the treatment led to a higher amount of hemicellulose. Lignin content increased after acid treatment at $120{ }^{\circ} \mathrm{C}$ using $0.5 \%$ of $\mathrm{H}_{2} \mathrm{SO}_{4}$. The processing time increase from 15 to 30 and 45 min at $2.5 \%$ of $\mathrm{H}_{2} \mathrm{SO}_{4}$, also led to the increase of lignin. Thus, the best $\mathrm{H}_{2} \mathrm{SO}_{4}$ treatment will be different for different target carbohydrates (lignin, hemicellulose, or cellulose) present in the recovered solid material.

The TMR obtained after the pretreatments ranged from 55.4 to $80.8 \%$, and the higher the $\mathrm{H}_{2} \mathrm{SO}_{4}$ percentages, the smaller the TMR values obtained due to a higher material solubilization, which occurred independently of the temperature and the processing time. In the pretreatments using 0.5 and $2.5 \%$ of $\mathrm{H}_{2} \mathrm{SO}_{4}$, both performed at $100{ }^{\circ} \mathrm{C}$ and $15 \mathrm{~min}$, the TMR decreased from $80.8 \%$ to $68.10 \%$ with the increasing acid concentration from $0.5 \%$ to $2.5 \%$, respectively. The same behavior was observed in the assays using $0.5 \%, 1.5 \%$, and $2.5 \%$ of acid at $110{ }^{\circ} \mathrm{C}$ for $30 \mathrm{~min}$, resulting in TMR of $65.4 \%, 63.3 \%$, and $57.8 \%$, respectively. It is known that the sulfuric acid reacts preferentially with the hemicellulose portion of the lignocellulosic materials due to its capacity to break covalent bonds, hydrogen bonds, and van der Waals forces [10].

Temperatures higher than $110{ }^{\circ} \mathrm{C}$ together with the pretreatments times higher than $30 \mathrm{~min}$ increased hemicellulose solubilization, confirming the estimated effects of these variables. The response surfaces corroborated the same optimum region. The maximum hemicellulose solubilization corresponds to assays at $120{ }^{\circ} \mathrm{C}$ using $2.5 \%$ of $\mathrm{H}_{2} \mathrm{SO}_{4}$ during 15 and $45 \mathrm{~min}$, and at $120{ }^{\circ} \mathrm{C}$ using $1.5 \%$ of the acid for $30 \mathrm{~min}$ (raw data available in Supporting Information). It is well known that initial solubilization of hemicellulose occurs, but cellulose solubilization can also take place simultaneously. Furthermore, the hemicellulose solubilization increases the cellulose digestibility [10]. However, cellulose should remain in the solid fraction of the material so it can be further hydrolyzed to glucose. Therefore, the pretreatment conditions chosen for the next steps (alkali pretreatment) were $\mathrm{H}_{2} \mathrm{SO}_{4} 1.5 \%, 120$ ${ }^{\circ} \mathrm{C}$, and $30 \mathrm{~min}$. Under these conditions, the cellulose content was maximum (54\%), with $68.7 \%$ of hemicellulose solubilization. In this case, the loss of cellulose by solubilization was $4.3 \%$, which correspond to the lesser amount among all the tested conditions.

The acid liquid fraction (hydrolysate) can be used as a xylose source in several bioprocesses with microorganisms able to metabolize this carbon source. However, the main constraints on acid pretreatment of lignocellulosic materials is the formation of furfural, 5-hydroxymethyl2 -furaldehyde (HMF), and acetic acid that are products of the sugar degradation released during the process due to high temperatures and low $\mathrm{pH}$ values. The presence of these compounds in the liquid fraction can compromise its further utilization in subsequent bioprocesses [29]. Therefore, in order to evaluate the effect of the experimental parameters temperature, time and percentage of sulfuric acid on the composition of the liquid fraction and the occurrence of aforementioned degradation products (furfural, acetic acid and xylose), an additional PCA was developed using the same assays data from the solid fraction analysis. Fig. 2 presents the PC $1 \times$ PC 2 scores coordinate system (left side) and the respective loadings (right side) from the evaluation of the liquid fraction composition (a), as well as the formation of the degradation
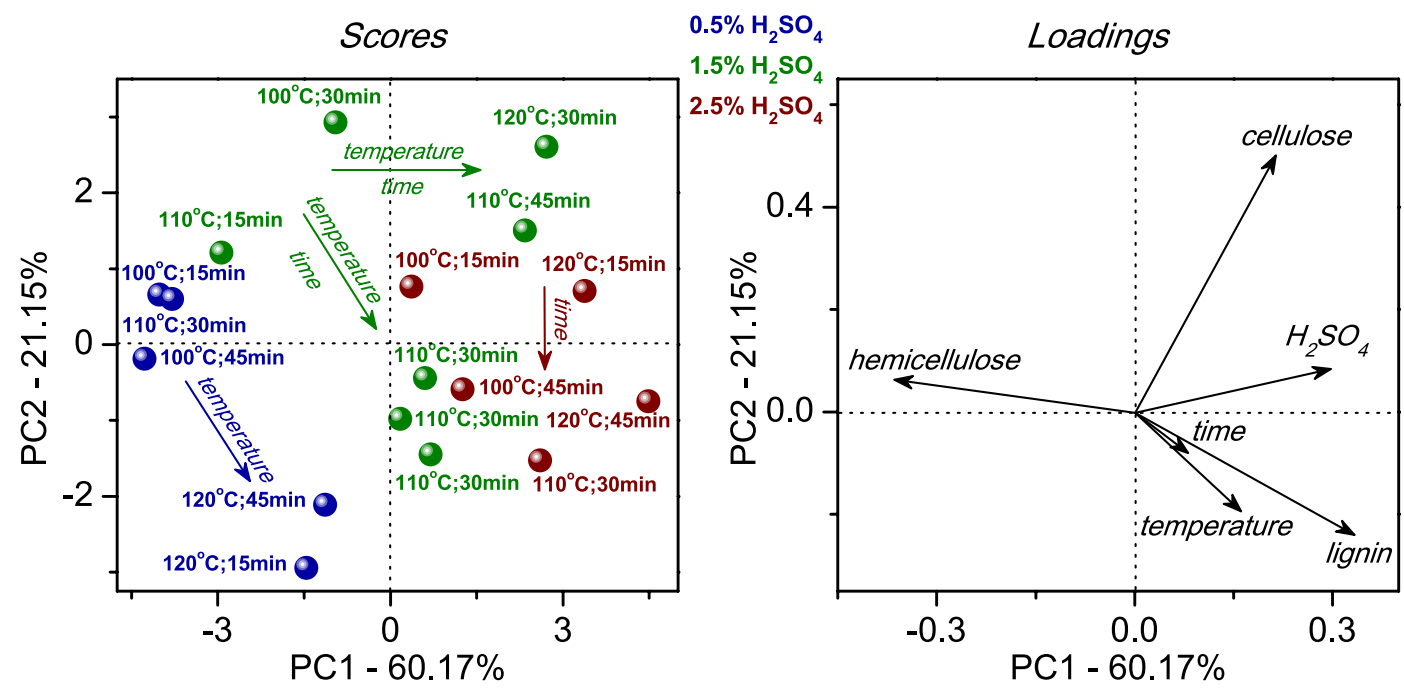

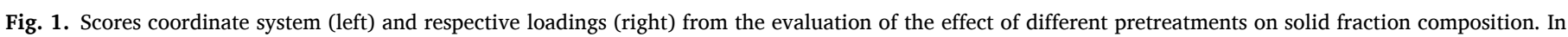

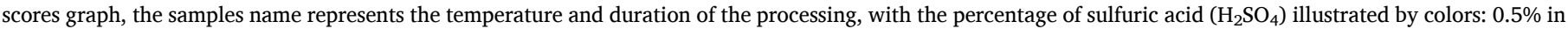

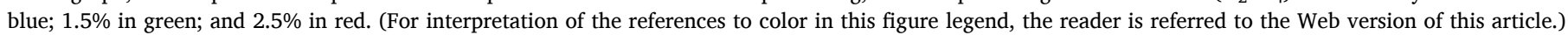


products (b), which retained $69.10 \%$ and $81.28 \%$ of the total data variance, respectively.

In general, the multivariate analysis highlighted the increase of cellulose and hemicellulose with the increase in the percentage of sulfuric acid, temperature, and time, which is in accordance with the analysis of the solid fraction (Fig. 1). The amounts of lignin were higher, using $0.5 \%$ of sulfuric acid in assays at $110^{\circ} \mathrm{C}$ for $30 \mathrm{~min}$, and at $100{ }^{\circ} \mathrm{C}$ for $45 \mathrm{~min}$. Furthermore, the PCA clearly showed increases of furfural, acetic acid, and xylose with the increase of sulfuric acid, and these compounds were found in higher amounts when the most severe conditions were used: $2.5 \%$ of sulfuric acid at $120^{\circ} \mathrm{C}$ during $45 \mathrm{~min}$.

The concentrations of xylose ranged from 0 to $13.6 \mathrm{~g} \mathrm{~L}^{-1}$ (values are available in Table S2 - Supporting Information). The higher xylose concentration was obtained for the pretreatment using $2.5 \% \mathrm{H}_{2} \mathrm{SO}_{4}$ at $125{ }^{\circ} \mathrm{C}$ for $45 \mathrm{~min}$, which was the same condition at which the highest amount of hemicellulose was solubilized $(75.1 \%)$. Acetic acid also increased with the increase of the acid concentration. The higher concentration of acetic acid was $3.6 \mathrm{~g} \mathrm{~L}^{-1}$ obtained using the most severe treatment $\left(2.5 \% \mathrm{H}_{2} \mathrm{SO}_{4}\right.$ at $120{ }^{\circ} \mathrm{C}$ for $\left.45 \mathrm{~min}\right)$.

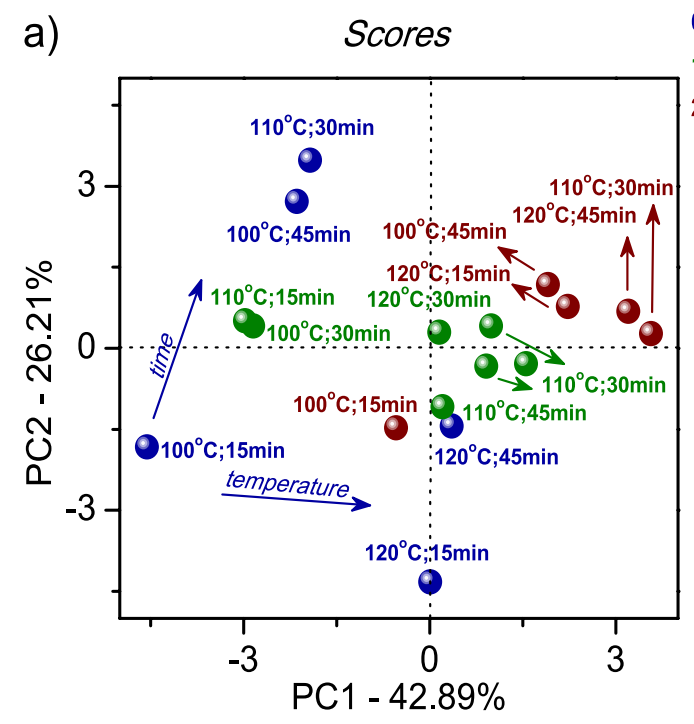

b)
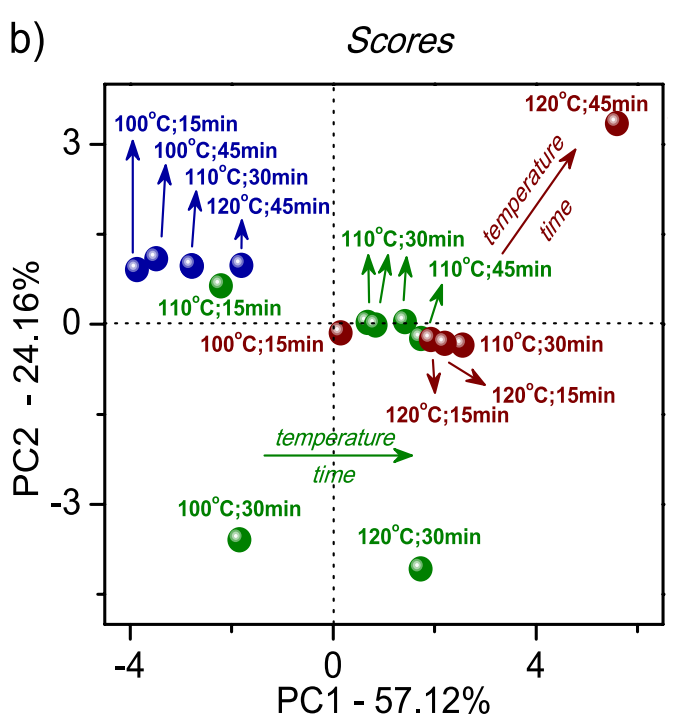

\subsection{Alkaline treatment of the vine pruning residue}

Hemicellulose and lignin are strongly linked to cellulose, and their removal is crucial to increase the accessibility of the enzymes to cellulose [30]. It is known that sodium hydroxide $(\mathrm{NaOH})$ is extensively used in this type of pretreatment because it increases the internal surface of cellulose and decreases its crystallinity degree [31], thus improving the enzyme access to cellulose. Thus, the acid pretreated vine pruning at the condition that led to the higher cellulose preservation in the solid fraction $\left(\mathrm{H}_{2} \mathrm{SO}_{4} 1.5 \%\right.$ at $120{ }^{\circ} \mathrm{C}$ for $\left.30 \mathrm{~min}\right)$ was further exposed to different concentrations of $\mathrm{NaOH}$ (values available in Supporting Information). In all tested conditions, the residual hemicellulose that was not previously solubilized in acid pretreatment, it was now completely solubilized.

The total mass recovery (TMR) after the treatments (acid + basic) ranged from $49.9 \%$ to $74.9 \%$, and the smallest TMR values were obtained when the highest $\mathrm{NaOH}$ concentrations were used. However, due to the high number of experiments and responses, a PCA method was developed to evaluate the effect of the different $\mathrm{NaOH}$ treatments on the vine pruning residue. Fig. 3 illustrates the PC1 $\times$ PC2 scores coordinate
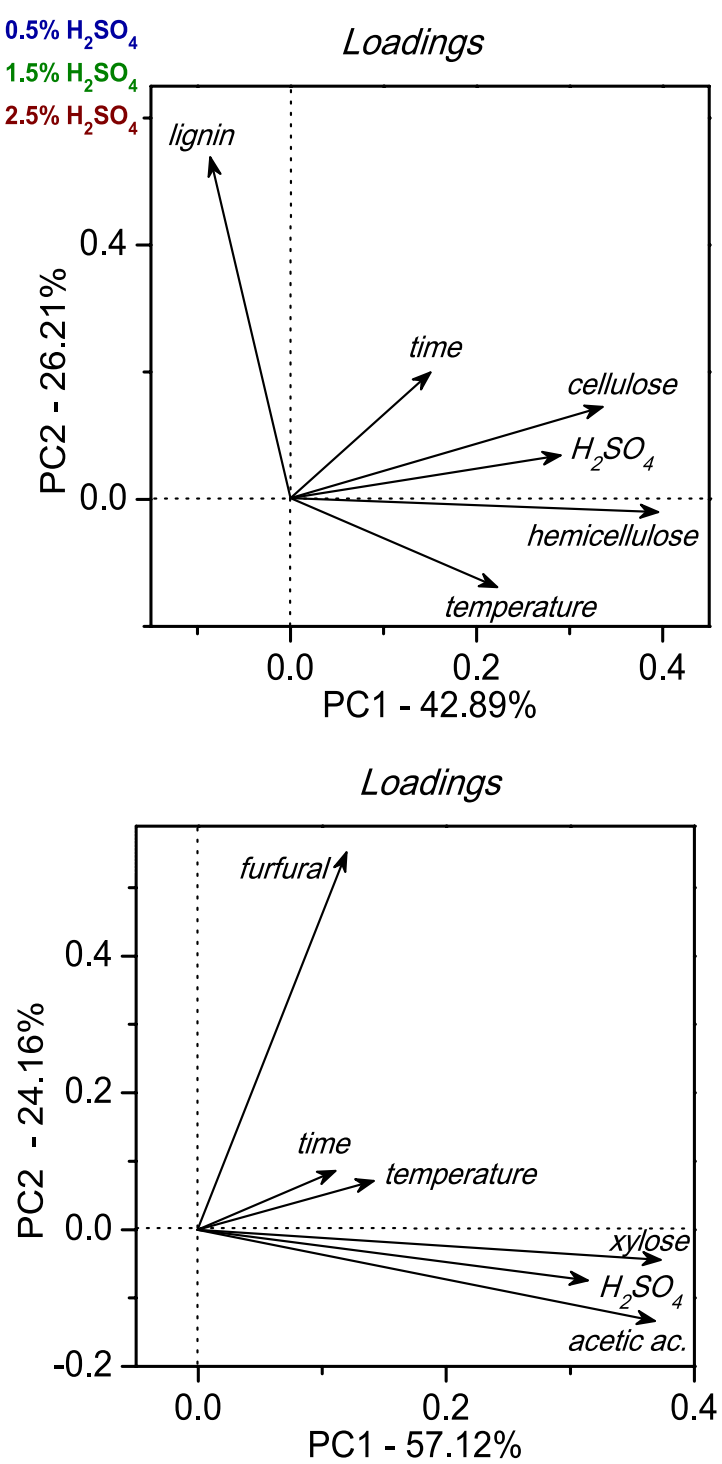

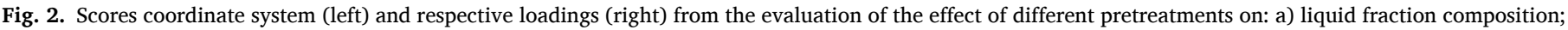

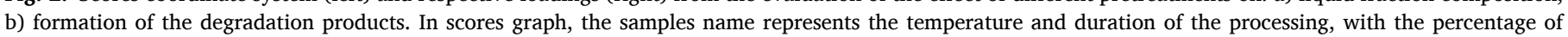

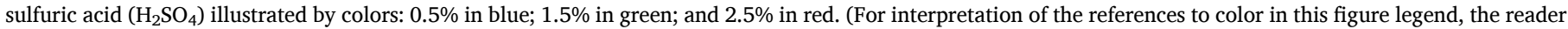
is referred to the Web version of this article.) 
system (left side) and the respective loadings (right side), which retained high total data variance $(99.97 \%)$.

In general, PC1 was the main axis for the sample scores $(99.75 \%$ of the variance of the sample), reveling increases in the amount of glucose and enzymatic hydrolysis yield by the $\mathrm{NaOH}$ treatment - yield of the cellulose/hemicellulose to glucose conversion. Also, based on the PC2 axis, the increases of the hydrolysis yield can be seen even on the acid pretreatment of the untreated sample - from positive to negative scores. However, this increase was much higher after all the alkaline assays. Furthermore, increases in the glucose concentration were found after all the alkali treatments. Also, the PC2 axis presented relevant information for discrimination of the alkaline assays based on the percentage of $\mathrm{NaOH}$, from the assays under lower percentages in negative scores to those under higher percentages in positive scores. The effect of the temperature was relevant only for the assay conducted with $2 \%$ of $\mathrm{NaOH}$ using the higher temperature $\left(120^{\circ} \mathrm{C}\right)$ placed at positive scores of PC2, and the lower temperature $\left(100^{\circ} \mathrm{C}\right)$ in negative scores of the same PC.

It can be concluded that treatments performed at $120{ }^{\circ} \mathrm{C}$ removed more lignin than those at $100{ }^{\circ} \mathrm{C}$. The percentages of solubilized lignin were $38.8 \%, 54.7 \%$, and $63.8 \%$ for assays at $1.0,2.0$, and $3.0 \%$ of $\mathrm{NaOH}$, respectively. The higher percentage of lignin $(63.8 \%)$ was solubilized when the pretreatment was performed with $3.0 \%$ of $\mathrm{NaOH}$ at $120{ }^{\circ} \mathrm{C}$ without agitation. The higher amount of cellulose solubilized was also obtained for these conditions. Additionally, amounts of solubilized cellulose did not exceed $10 \%$ in all assays performed at $100{ }^{\circ} \mathrm{C}$. However, the condition that removed the highest amounts of lignin was $100{ }^{\circ} \mathrm{C}$ under $3.0 \%$ of $\mathrm{NaOH}$. As the choice of the delignification process should be made based on the highest removal of lignin and the lowest to no solubilization of cellulose, along with the maximal enzymatic hydrolysis yields [10], all resultant samples from the alkali treatment were further submitted to enzymatic hydrolysis.

\subsection{Enzymatic hydrolysis of the treated vine pruning}

Initially, an evaluation by PCA was performed to have an overview of the enzymatic hydrolyses and visualize the relationship between lignin and cellulose from solid and liquid fractions according to the variation of the temperature and percentage of $\mathrm{NaOH}$. Fig. 4 illustrates the PC1 $\times$ PC2 scores coordinate system (left side) and the respective loadings (right side) from the exploratory multivariate evaluation, which retained high total data variance $(76.53 \%)$.

A higher effect of the temperature compared to the percentage of
$\mathrm{NaOH}$ was clearly detected, with the increase in the amounts of cellulose and lignin in the solid and liquid fractions as a result of the increase of temperature from $100{ }^{\circ} \mathrm{C}$ to $120^{\circ} \mathrm{C}$. Also, variations in the $\mathrm{NaOH}$ percentage were relevant only at $120{ }^{\circ} \mathrm{C}$, with an increase of the lignin content in the liquid fraction, as well as increases of cellulose in the solid and liquid fractions as a result of the increase of $\mathrm{NaOH}$. On the other hand, an increase of lignin in the solid fraction was detected with a decrease in the percentage of $\mathrm{NaOH}$ at $120^{\circ} \mathrm{C}$. Therefore, increasing the temperature from $100^{\circ} \mathrm{C}$ to $120^{\circ} \mathrm{C}$ led to a higher level of lignin removal in all the alkali pretreated samples. In these same conditions, the content of cellulose solubilized increased (data available in Table $3 \mathrm{~S}$ - Supporting Information).

Regarding the enzymatic hydrolysis of the treated vine pruning, the enzymes were not able to hydrolyze the untreated vine pruning as expected, and the hydrolysis of the vine pruning treated only with sulfuric acid released $2.17 \mathrm{~g} \mathrm{~L}^{-1}$ of glucose after $96 \mathrm{~h}$ (Table 1). Diluted acid pretreatment usually hydrolyzes hemicellulose to xylose and alters the lignin structure. Despite previous studies reported proper glucose release using a diluted acid pretreatment, to achieve good cellulose conversion, high temperatures $\left(>160^{\circ} \mathrm{C}\right)$ are required. The combination of high temperature and diluted sulfuric acid imparts severe corrosion process in industrial equipment. These conditions also promote the hemicellulose sugars decomposition, forming furfural, and hydroxymethylfurfural (HMF), which are toxic and inhibit microbial growth [32]. On the other hand, alkali treatment removes lignin, and the hydrolysis of all vine pruning residues submitted to alkali treatment after the acid pretreatment presented similar profiles. The highest glucose rate released was detected in the first $24 \mathrm{~h}$ of hydrolysis in all assays. The highest glucose concentrations ( 30 and $35 \mathrm{~g} \mathrm{~L}^{-1}$ ) were obtained after 72 $h$. The glucose concentration obtained from the hydrolysis of the residue after the pretreatment using $1.0 \%$ of $\mathrm{NaOH}$ at $120^{\circ} \mathrm{C}$ without agitation was 14.5 times higher than the amount released using the material pretreated only with acid.

Under the same $\mathrm{NaOH}$ concentration, the results were not significantly different based on the ANOVA after $96 \mathrm{~h}$, which strengthens the need to combine the amount of lignin removal with the treatment, and the cellulose solubilized after the enzyme hydrolysis to choose the best conditions to apply to a given material. The complete removal of the lignin may not be required for the enzyme hydrolysis of cellulose. In the present study, the highest glucose concentration and glucose yield by the enzymatic hydrolysis was obtained from the treatment of the vine pruning residue after the pretreatment using $2.0 \%$ of $\mathrm{NaOH}$, at $100{ }^{\circ} \mathrm{C}$
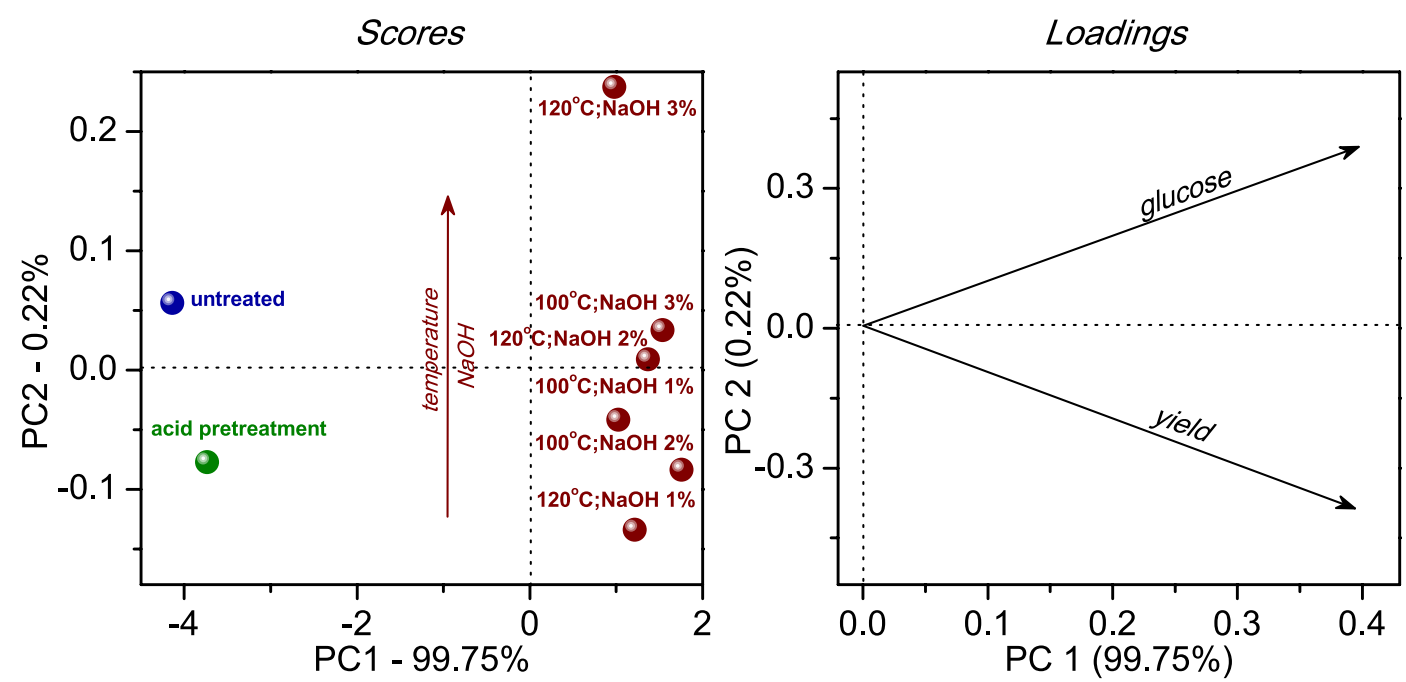

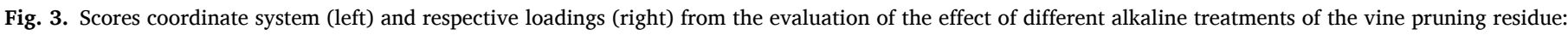

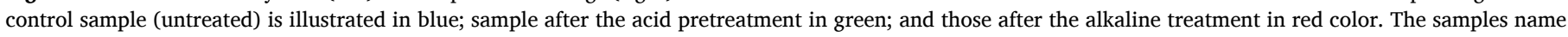

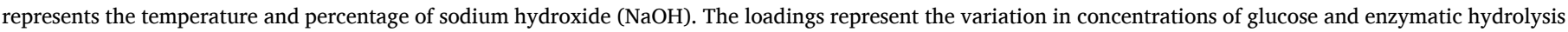
yield. (For interpretation of the references to color in this figure legend, the reader is referred to the Web version of this article.) 
Scores

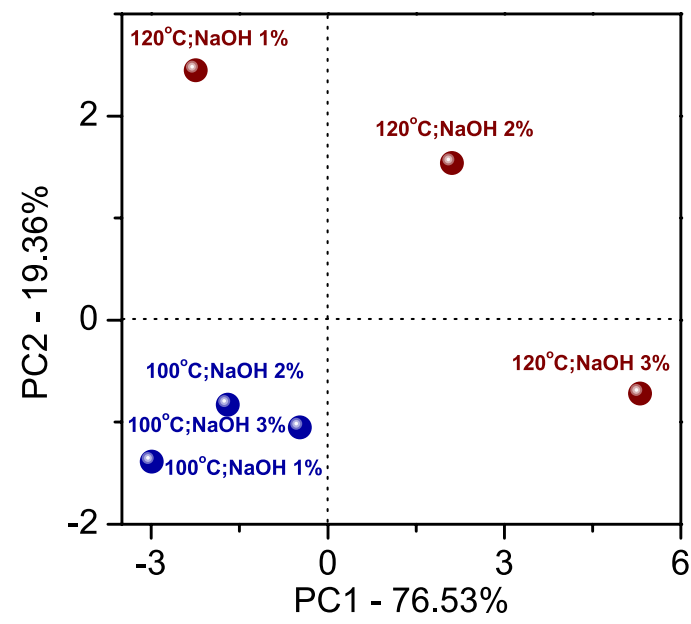

Loadings

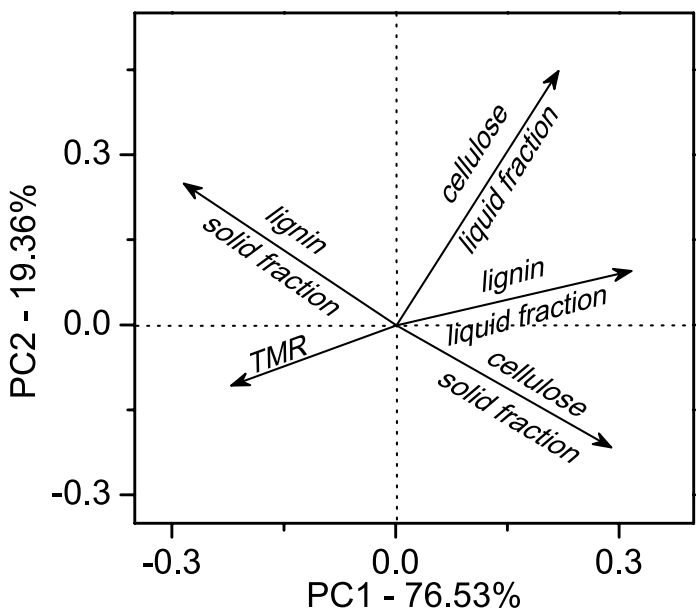

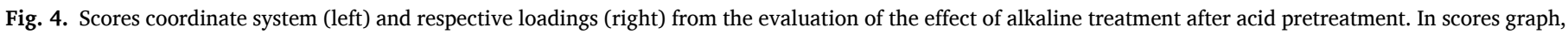

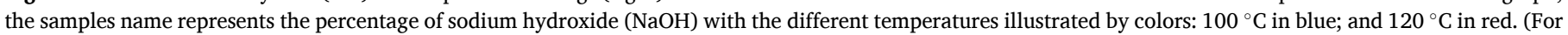
interpretation of the references to color in this figure legend, the reader is referred to the Web version of this article.)

Table 1

Concentrations of glucose and enzymatic hydrolysis yield (yield of the cellulose/ hemicellulose to glucose conversion) after $96 \mathrm{~h}$ of enzymatic hydrolysis of vine pruning. Legend: UNT - untreated vine pruning; PT0 - vine pruning pretreated with sulfuric acid $\left(1.5 \% \mathrm{H}_{2} \mathrm{SO}_{4}, 120{ }^{\circ} \mathrm{C}\right.$ and $30 \mathrm{~min}$ - assay 10); PT1, PT3 and PT5 refer to pretreatment that was realized at $120^{\circ} \mathrm{C}$ without agitation and with $1.0 \%, 2.0 \%$ and $3.0 \%$ of $\mathrm{NaOH}$, respectively and PT2, PT4 and PT6 refer to a pretreatment at $100{ }^{\circ} \mathrm{C}$ with agitation and with $1.0 \%, 2.0 \%$ and $3.0 \%$ of $\mathrm{NaOH}$, respectively).

\begin{tabular}{lll}
\hline Pretreatment condition & Glucose $(\mathrm{g} / \mathrm{L})$ & Yield (\%) \\
\hline Untreated (UNT) & $0.56 \pm 0.10$ & - \\
PT0 & $2.17 \pm 0.1$ & $8.8 \pm 0.4$ \\
PT1 & $31.46 \pm 0.7^{\mathrm{ab}}$ & $90.78 \pm 1.9^{\mathrm{ab}}$ \\
PT2 & $30.80 \pm 0.0^{\mathrm{a}}$ & $86.31 \pm 0.0^{\mathrm{ac}}$ \\
PT3 & $33.22 \pm 0.6^{\mathrm{bcd}}$ & $90.96 \pm 1.6^{\mathrm{ab}}$ \\
PT4 & $35.06 \pm 1.2^{\mathrm{d}}$ & $98.72 \pm 3.4^{\mathrm{d}}$ \\
PT5 & $32.26 \pm 0.4^{\mathrm{abc}}$ & $80.86 \pm 1.2^{\mathrm{c}}$ \\
PT6 & $34.35 \pm 0.4^{\mathrm{cd}}$ & $93.35 \pm 1.1^{\mathrm{bd}}$ \\
\hline
\end{tabular}

Different overwritten letters in the same column indicate significant differences in the values of averages $(\mathrm{p}<0.05$ ) in accordance with Tukey's test.

without agitation, which did not result in the highest lignin removal as presented in Table 1.

Additionally, in 2010, a study of combined pretreatment of wood chips was reported [33]. The residue was first submitted to the steam explosion and then to delignification. The hydrolysis of the treated material led to a $95.5 \%$ glucose yield. Similar results were reported for sugarcane bagasse submitted to the steam explosion and alkali treatment [34]. When the pretreatment replaced the steam explosion with diluted acid and alkali treatment, the glucose yield was only $79 \%$ for sugarcane bagasse [34]. For the same residue, the combination of the acid pretreatment with ionic liquid resulted in a glucose yield of $95.5 \%$ [35]. The acid pretreatment of olive pruning (under different conditions of those tested in the current work) was also studied and a glucose yield of $76.5 \%$ was reported [36]. The enzyme hydrolysis of barley straw submitted to acid treatment resulted in a $61.7 \%$ glucose yield [10]. A recent study showed the pretreatment of corn stover by the steam explosion with sulfuric acid, which led to a glucose yield of $84.7 \%$ after enzymatic hydrolysis [37]. In the present study, the glucose yield from the enzymatic hydrolysis of the vine pruning pretreated with acid was $8.8 \%$. The low glucose yield obtained with the acid pretreated was not enough to decrease the material crystallinity allowing the enzyme access to the cellulose portion as seen in the SEM images presented in section
3.5.

\subsection{Structural analysis of the biomass}

The main constituents of the cell wall from plants are cellulose, hemicellulose, and lignin distributed in one primary wall and a secondary wall with three layers. Usually, the primary wall has more lignin than the secondary wall. In general, plant tissues are parenchyma, collenchyma, xylem, and sclerenchyma. The parenchyma is rich in cellulose, the collenchyma in hemicellulose, and the xylem and sclerenchyma in lignin $[38,39]$. Therefore, to evaluate the changes promoted by the previously discussed vine pruning processing, the structures of the vine pruning before and after the treatments were analyzed by Scanning Electronic Microscopy (SEM). Fig. 5 presents the images from parenchyma, sclerenchyma, and xylem of the untreated vine pruning (UNT); the PT0 refers to vine pruning pretreated under $1.5 \% \mathrm{H}_{2} \mathrm{SO}_{4}$, $120^{\circ} \mathrm{C}$ and $30 \mathrm{~min}$ (assay selected to alkaline treatment); PT1, PT3, and PT5 refer to the pretreatments under $120{ }^{\circ} \mathrm{C}$ without agitation with $1.0 \%, 2.0 \%$, and $3.0 \%$ of $\mathrm{NaOH}$, respectively; and PT2, PT4, and PT6 refer to pretreatments at $100{ }^{\circ} \mathrm{C}$ under agitation with $1.0 \%, 2.0 \%$, and $3.0 \%$ of $\mathrm{NaOH}$, respectively. The respective concentrations of glucose and the yield after $96 \mathrm{~h}$ of enzymatic hydrolysis of vine pruning according to each assay are described in Supporting Information.

The untreated vine pruning showed complete and compact parenchyma, sclerenchyma, and xylem. The vine pruning residue pretreated at $120^{\circ} \mathrm{C}$ under $1.5 \%$ of $\mathrm{H}_{2} \mathrm{SO}_{4}$ during $30 \mathrm{~min}$ showed a slight opening of the parenchyma structure (structure composed mainly of cellulose and hemicellulose). However, it was still possible to observe the original vegetable cell contours. The sclerenchyma and xylem remained intact. In PT1 assay, where the acid pretreatment was followed by $\mathrm{NaOH} 1 \%$ $(\mathrm{w} / \mathrm{v})$ at $120^{\circ} \mathrm{C}$ without agitation, the parenchyma degradation started, and the SEM micrograph showed the parenchyma with unstructured areas and intact areas. The contours of the original cell were not observed. The xylem remained preserved, and the sclerenchyma was slightly modified. The parenchyma from the sample of treatment PT2 $\left(100{ }^{\circ} \mathrm{C}\right.$ and $\left.\mathrm{NaOH} 1 \%\right)$ was similar to the one from PT1, and the sclerenchyma exhibited some tiny holes at surface. The samples from the treatments with $2.0 \%$ of $\mathrm{NaOH}$, one at $120^{\circ} \mathrm{C}(\mathrm{PT} 3)$ and other at $100{ }^{\circ} \mathrm{C}$ (PT4), showed more degraded parenchyma with tiny holes at the surface. The cell structure was also disorganized due to the chemical action. Regarding the sample from PT3, the alkali acted on the xylem structure, and some cracks are seen on the residue surface. In the samples, PT5 and 


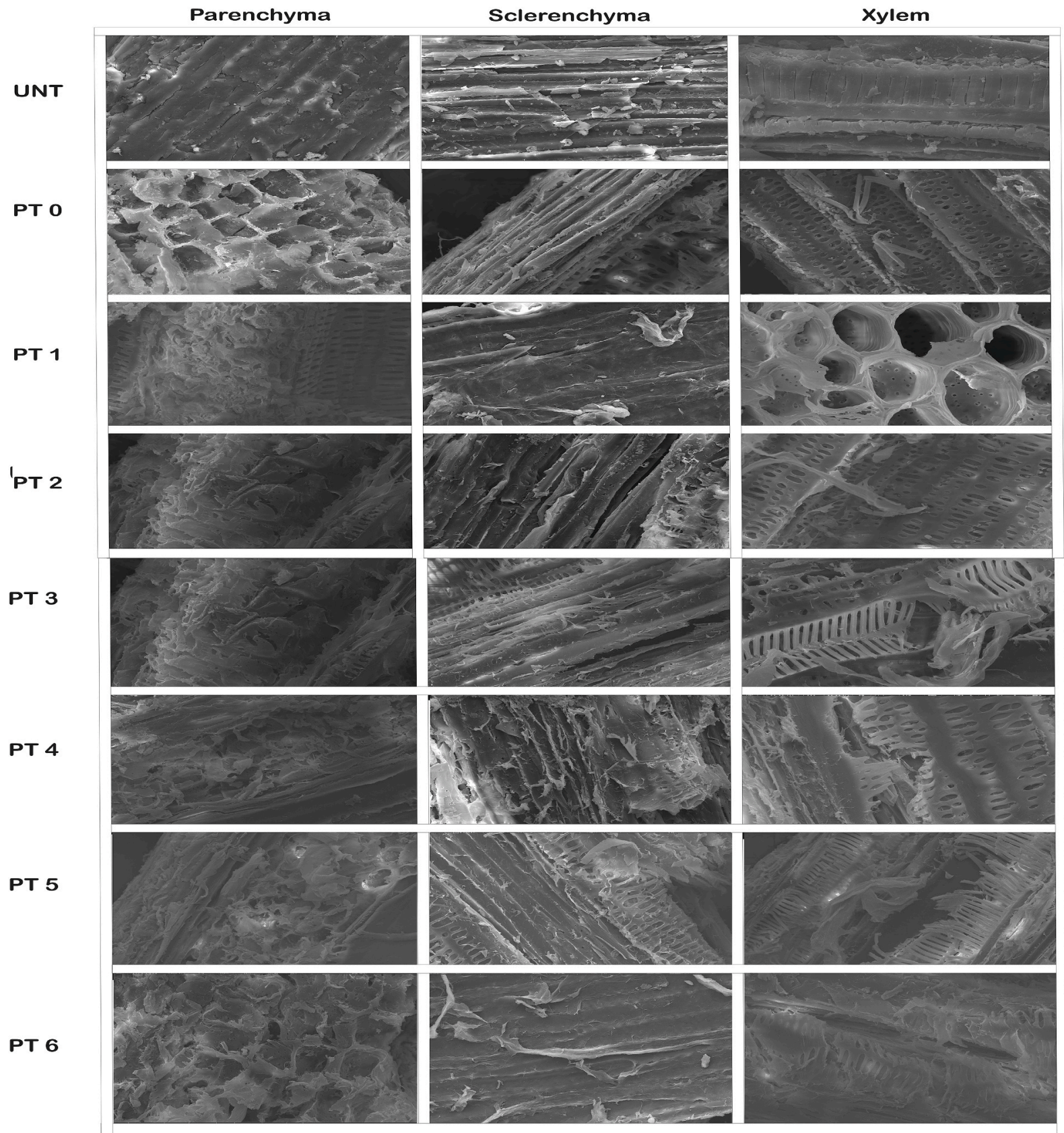

Fig. 5. Structures of the parenchyma, sclerenchyma, and xylem from vine pruning: untreated - UNT; pretreated under $1.5 \% \mathrm{H}_{2} \mathrm{SO}_{4}, 120{ }^{\circ} \mathrm{C}$ and 30 min - PT0; $\mathrm{PT} 1$, PT3, and PT5 refer to the pretreatments under $120^{\circ} \mathrm{C}$ without agitation with $1.0 \%, 2.0 \%$, and $3.0 \%$ of $\mathrm{NaOH}$, respectively; PT2, PT4, and PT6 refer to pretreatments at $100{ }^{\circ} \mathrm{C}$ under agitation with $1.0 \%, 2.0 \%$, and $3.0 \%$ of $\mathrm{NaOH}$, respectively.

PT6, the lignocellulosic structure of vine pruning was significantly destroyed. The sclerenchyma seems to have exploded, and the xylem showed many cracks. The results suggest that the $\mathrm{NaOH}$ concentration affected more the lignocellulosic structure than the temperature. These results corroborated with those observed in the quantitative analysis previously reported in section 3.4.

The structure of the vine pruning residues after enzymatic hydrolysis was also analyzed by SEM, and the results are shown in Fig. 6. The hydrolysis was performed at the same conditions for all assays since the aim was to evaluate the effect of the treatment on the subsequent enzyme. The material obtained from the enzymatic hydrolysis became porous breaking up by manual maceration, and therefore, it was possible to observe which structure of vine pruning was damaged.

The parenchyma was partially destroyed with small fissures (or cracks) at the surface as indicated by arrows. However, it was still possible to observe the original cell contours (PT1). The images of the samples PT2, PT3, PT5, and PT6 showed a parenchyma destroyed and the contours of the original cell were not observed anymore. The structure of the sample PT4 (Pretreatment under $2.0 \%$ of $\mathrm{NaOH}$ at 100 ${ }^{\circ} \mathrm{C}$ with agitation) exhibited the most destroyed kneaded aspect. This result was fully aligned with the quantitative hydrolysis of glucose yield of $98.7 \%$.

\section{Conclusions}

Acid pretreatment using $\mathrm{H}_{2} \mathrm{SO}_{4} \quad 1.5 \%$ at $120{ }^{\circ} \mathrm{C}$ during $30 \mathrm{~min}$ (autoclave) followed by delignification with $\mathrm{NaOH} 2.0 \%$ at $100{ }^{\circ} \mathrm{C}$ during $60 \mathrm{~min}$ led to the greatest glucose yield $(98.72 \%$ with $35.06 \mathrm{~g}$ 


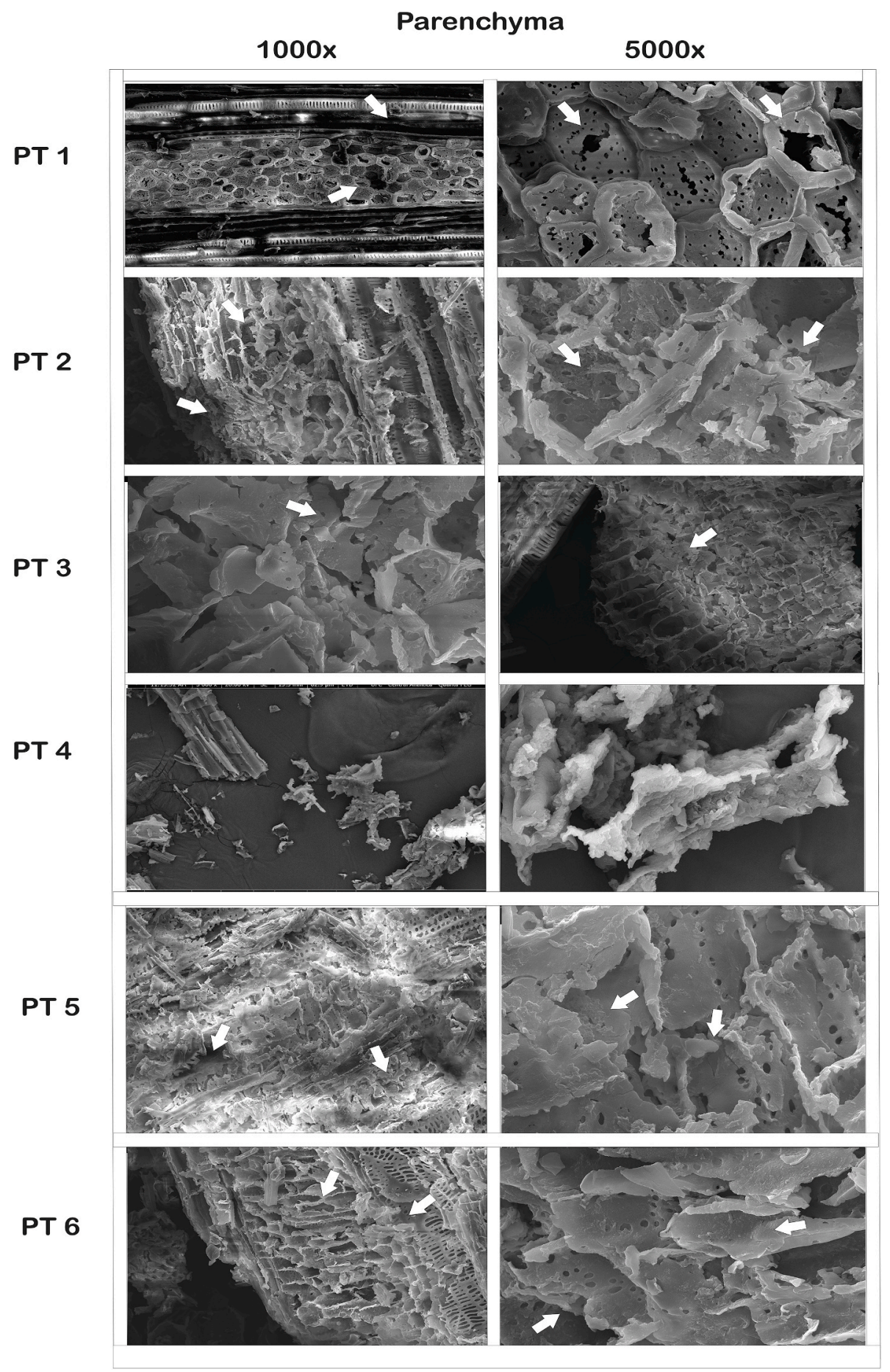

Fig. 6. Structures of the parenchyma from vine pruning after enzymatic hydrolysis: PT1, PT3, and PT5 refer to the pretreatments under $120{ }^{\circ} \mathrm{C}$ without agitation with $1.0 \%, 2.0 \%$, and $3.0 \%$ of $\mathrm{NaOH}$, respectively; PT2, PT4, and PT6 refer to pretreatments at $100{ }^{\circ} \mathrm{C}$ under agitation with $1.0 \%, 2.0 \%$, and $3.0 \%$ of $\mathrm{NaOH}$, respectively.

$\mathrm{L}^{-1}$ ). The two-step acid-alkali pretreatment removed the lignin opening the fiber structure, which allowed the enzyme action and therefore, the material saccharification. The SEM images clearly showed the action of the enzyme on the parenchyma, ultimately leading to saccharification with high glucose yields. The low levels of acetic acid, furfural, and HMF in the liquid fraction enable its further use, after neutralization, in bioprocesses involving xylose fermentation. Most of the published studies on lignocellulose hydrolysis suggest that the best pretreatment is the one removing the higher amounts of lignocellulose. The current study demonstrated, by SEM images and chemical analysis, that the highest hydrolysis yield and glucose concentration after enzyme hydrolysis is not directly related to the highest lignin removal, and that the enzyme hydrolysis results must be taken into account when choosing the pretreatment to be used.

\section{Acknowledgements}

This study was supported by the Portuguese Foundation for Science and Technology (FCT) under the scope of the strategic funding of UIDB/ 04469/2020 unit, BioTecNorte operation (NORTE-01-0145-FEDER000004), the projects Multibiorefinery (POCI-01-0145-FEDER-016403), FoSynBio (POCI-01-0145-FEDER-029549) and Lignozymes (POCI-01- 
0145-FEDER-029773) funded by the European Regional Development Fund under the scope of Norte 2020. In Brazil, this study was funded in part by the Coordenação de Aperfeiçoamento de Pessoal de Nível Superior (CAPES) - Finance Code 001, Conselho Nacional de Desenvolvimento Científico e Tecnológico (CNPq) and Fundação Cearense de Apoio ao Desenvolvimento Científico e Tecnológico (FUNCAP). The authors would like to acknowledge the Central Analytical (Physical Department) of Federal University of Ceará for conducting the SEM analysis and the Centro de Tecnologia Canavieira - CTC/Brazil for the support. E. Gudiña and L. Rodrigues acknowledge FCT for the Post-doctoral (CEB-BPD/01/ 2015/07) and sabbatical (SFRH/BSAB/142991/2019) grants, respectively.

\section{Appendix A. Supplementary data}

Supplementary data to this article can be found online at https://doi. org/10.1016/j.biombioe.2020.105653.

\section{References}

[1] P.S. Brito, A.S. Oliveira, L.F. Rodrigues, Energy valorization of solid vines pruning by thermal gasification in a pilot plant, Waste and biomass Valorization 5 (2) (2014) 181-187.

[2] S. Miller, F. Broom, T. Thorp, A. Barnett, Effects of leader pruning on vine architecture, productivity and fruit quality in kiwifruit (Actinidia deliciosa cv. Hayward), Sci. Hortic. 91 (3-4) (2001) 189-199.

[3] X. Vecino, L. Rodríguez-López, E.J. Gudiña, J. Cruz, A. Moldes, L. Rodrigues, Vineyard pruning waste as an alternative carbon source to produce novel biosurfactants by Lactobacillus paracasei, J. Ind. Eng. Chem. 55 (2017) 40-49.

[4] G. Bustos, A.B. Moldes, J.M. Cruz, J.M. Domínguez, Production of lactic acid from vine-trimming wastes and viticulture lees using a simultaneous saccharification fermentation method, J. Sci. Food Agric. 85 (3) (2005) 466-472.

[5] G.A. Ntalos, A.H. Grigoriou, Characterization and utilisation of vine prunings as a wood substitute for particleboard production, Ind. Crop. Prod. 16 (1) (2002) 59-68.

[6] E. Biagini, F. Barontini, L. Tognotti, Gasification of agricultural residues in a demonstrative plant: vine pruning and rice husks, Bioresour. Technol. 194 (2015) 36-42.

[7] A. Moldes, G. Bustos, A. Torrado, J. Domínguez, Comparison between different hydrolysis processes of vine-trimming waste to obtain hemicellulosic sugars for further lactic acid conversion, Appl. Biochem. Biotechnol. 143 (3) (2007) 244-256.

[8] H.Y. Yoo, J.H. Lee, D.S. Kim, J.H. Lee, S.K. Lee, S.J. Lee, et al., Enhancement of glucose yield from canola agricultural residue by alkali pretreatment based on multi-regression models, J. Ind. Eng. Chem. 51 (2017) 303-311.

[9] P.V. de Arruda, J.C. dos Santos, RdCLB. Rodrigues, D.D.V. da Silva, C. K. Yamakawa, G.J. de Moraes Rocha, et al., Scale up of xylitol production from sugarcane bagasse hemicellulosic hydrolysate by Candida guilliermondii FTI 20037, J. Ind. Eng. Chem. 47 (2017) 297-302.

[10] M. Yang, J. Zhang, S. Kuittinen, J. Vepsäläinen, P. Soininen, M. Keinänen, et al., Enhanced sugar production from pretreated barley straw by additive xylanase and surfactants in enzymatic hydrolysis for acetone-butanol-ethanol fermentation, Bioresour. Technol. 189 (2015) 131-137.

[11] C.-H. Su, M.-H. Chung, H.-J. Hsieh, Y.-K. Chang, J.-C. Ding, H.-M. Wu, Enzymatic hydrolysis of lignocellulosic biomass in ionic liquid media for fermentable sugar production, J Taiwan Institute of Chem Eng 43 (4) (2012) 573-577.

[12] J.S. Lim, Z.A. Manan, S.R.W. Alwi, H. Hashim, A review on utilisation of biomass from rice industry as a source of renewable energy, Renew. Sustain. Energy Rev. 16 (5) (2012) 3084-3094.

[13] N. Sarkar, S.K. Ghosh, S. Bannerjee, K. Aikat, Bioethanol production from agricultural wastes: an overview, Renew. Energy 37 (1) (2012) 19-27.

[14] M. Narra, J.P. James, V. Balasubramanian, Simultaneous saccharification and fermentation of delignified lignocellulosic biomass at high solid loadings by a newly isolated thermotolerant Kluyveromyces sp. for ethanol production, Bioresour. Technol. 179 (2015) 331-338.

[15] G.D. Saratale, M.-Y. Jung, M.-K. Oh, Reutilization of green liquor chemicals for pretreatment of whole rice waste biomass and its application to 2,3-butanediol production, Bioresour. Technol. 205 (2016) 90-96.
[16] D. Banerjee, S. Mukherjee, S. Pal, S. Khowala, Enhanced saccharification efficiency of lignocellulosic biomass of mustard stalk and straw by salt pretreatment, Ind. Crop. Prod. 80 (2016) 42-49.

[17] A.L. Woiciechowski, C.J.D. Neto, L.P. de Souza Vandenberghe, D.P. de Carvalho Neto, A.C.N. Sydney, L.A.J. Letti, et al., Lignocellulosic biomass: acid and alkaline pretreatments and their effects on biomass recalcitrance-conventional processing and recent advances, Bioresour. Technol. (2020), 122848.

[18] C.L.B. Reis, LMAe Silva, T.H.S. Rodrigues, A.K.N. Félix, RSd Santiago-Aguiar, K. M. Canuto, et al., Pretreatment of cashew apple bagasse using protic ionic liquids: enhanced enzymatic hydrolysis, Bioresour. Technol. 224 (2017) 694-701.

[19] S. Mateo, J.G. Puentes, I.C. Roberto, S. Sánchez, A.J. Moya, Optimization of acid hydrolysis of olive tree pruning residue, Ferm Candida Guilliermondii. Biomass and Bioenergy 69 (2014) 39-46.

[20] M. Cuevas, J.F. García, S. Sánchez, Enhanced enzymatic hydrolysis of pretreated almond-tree prunings for sugar production, Carbohydr. Polym. 99 (2014) 791-799.

[21] C. Buratti, D. Foschini, M. Barbanera, F. Fantozzi, Fermentable sugars production from peach tree prunings: response surface model optimization of $\mathrm{NaOH}$ alkaline pretreatment, Biomass Bioenergy 112 (2018) 128-137.

[22] S. Ferreira, A.P. Duarte, M.H.L. Ribeiro, J.A. Queiroz, F.C. Domingues, Response surface optimization of enzymatic hydrolysis of Cistus ladanifer and Cytisus striatus for bioethanol production, Biochem. Eng. J. 45 (3) (2009) 192-200.

[23] R.N. Maeda, C.A. Barcelos, L.M.M.S. Anna, N. Pereira, Cellulase production by Penicillium funiculosum and its application in the hydrolysis of sugar cane bagasse for second generation ethanol production by fed batch operation, J. Biotechnol. 163 (1) (2013) 38-44.

[24] N. Dowe, SSF experimental protocols lignocellulosic biomass hydrolysis and fermentation : laboratory analytical procedure (LAP) : issue date, 10/30/2001, in: J.D. McMillan (Ed.), Golden, Colo., National Renewable Energy Laboratory, 2008.

[25] U.S. Government, Determination of Structural Carbohydrates and Lignin in Biomass: Laboratory Analytical Procedure (LAP), General Books LLC, 2012.

[26] E.G. Alves Filho, V.M. Sousa, S. Rodrigues, E.S. de Brito, F.A. Fernandes, Green ultrasound-assisted extraction of chlorogenic acids from sweet potato peels and sonochemical hydrolysis of caffeoylquinic acids derivatives, Ultrason. Sonochem. 63 (2020), 104911.

[27] J.V.B. Freitas, E.G. Alves Filho, L.M.A. Silva, G.J. Zocolo, E.S. de Brito, N. V. Gramosa, Chemometric analysis of NMR and GC datasets for chemotype characterization of essential oils from different species of Ocimum, Talanta 180 (2018) 329-336.

[28] DMd Carvalho, O. Sevastyanova, L.S. Penna, BPd Silva, M.E. Lindström, J. L. Colodette, Assessment of chemical transformations in eucalyptus, sugarcane bagasse and straw during hydrothermal, dilute acid, and alkaline pretreatments, Ind. Crop. Prod. 73 (2015) 118-126.

[29] H.S. Hafid, A.R. Nor 'Aini, M.N. Mokhtar, A.T. Talib, A.S. Baharuddin, M.S. Umi Kalsom, Over production of fermentable sugar for bioethanol production from carbohydrate-rich Malaysian food waste via sequential acid-enzymatic hydrolysis pretreatment, Waste Manag. 67 (2017) 95-105.

[30] S. Sun, S. Sun, X. Cao, R. Sun, The role of pretreatment in improving the enzymatic hydrolysis of lignocellulosic materials, Bioresour. Technol. 199 (2016) 49-58.

[31] P. Alvira, E. Tomás-Pejó, M. Ballesteros, M.J. Negro, Pretreatment technologies for an efficient bioethanol production process based on enzymatic hydrolysis: a review, Bioresour. Technol. 101 (13) (2010) 4851-4861.

[32] A. Verardi, I. De Bari, E. Ricca, V. Calabrò, Hydrolysis of lignocellulosic biomass: current status of processes and technologies and future perspectives, Bioethanol (2012) 95-122.

[33] L. Kumar, R. Chandra, P.A. Chung, J. Saddler, Can the same steam pretreatment conditions be used for most softwoods to achieve good, enzymatic hydrolysis and sugar yields? Bioresour. Technol. 101 (20) (2010) 7827-7833.

[34] G.J.M. Rocha, A.R. Gonçalves, S.C. Nakanishi, V.M. Nascimento, V.F.N. Silva, Pilot scale steam explosion and diluted sulfuric acid pretreatments: comparative study aiming the sugarcane bagasse saccharification, Ind. Crop. Prod. 74 (2015) 810-816.

[35] L.-Q. Jiang, Z. Fang, X.-K. Li, J. Luo, S.-P. Fan, Combination of dilute acid and ionic liquid pretreatments of sugarcane bagasse for glucose by enzymatic hydrolysis, Process Biochem. 48 (12) (2013) 1942-1946.

[36] C. Cara, E. Ruiz, J.M. Oliva, F. Sáez, E. Castro, Conversion of olive tree biomass into fermentable sugars by dilute acid pretreatment and enzymatic saccharification, Bioresour. Technol. 99 (6) (2008) 1869-1876.

[37] S. Shao, J. Zhang, W. Hou, A.S. Qureshi, J. Bao, Lower pressure heating steam is practical for the distributed dry dilute sulfuric acid pretreatment, Bioresour. Technol. 238 (2017) 744-748.

[38] A. Fahn, Plant Anatomy, Pergamon Press, 1967.

[39] L.J. Gibson, The hierarchical structure and mechanics of plant materials, J. R. Soc. Interface 9 (76) (2012) 2749-2766. 